\title{
La intervención de los sujetos privados en el delito de peculado: ¿Coautores?
}

\section{The Intervention of Private Subjects in the Crime of Embezzlement of Official Property by a Public Official: Joint Perpetrators?}

Juan Nicolás Cevallos Vallejo*

Kenny Jossue Espín DuQue**

Recibido / Received: 30/01/2020

Aceptado / Accepted: 30/03/2021

DOI: https://doi.org/10.18272/ulr.v8i1.2192

\section{Citación:}

Cevallos Vallejo, J.N., Espín Duque, K.J. «La intervención de los sujetos privados en el delito de peculado: ¿Coautores?». USFQ Law Review, Vol 8, no 1, mayo de 2021, pp. 237 - 258, doi: $10.18272 /$ ulr.v8i1.2192

\footnotetext{
* Universidad San Francisco de Quito USFQ, estudiante del Colegio de Jurisprudencia, casilla postal 17-1200-841, Quito 170901, Pichincha, Ecuador. Correo electrónico: jncevallos@estud.usfq.edu.ec / nicolascevallos17@gmail.com ORCID iD: https://orcid.org/0000-0001-7414-7118

** Universidad San Francisco de Quito USFQ, estudiante del Colegio de Jurisprudencia, casilla postal 17-1200-841, Quito 170901, Pichincha, Ecuador. Correo electrónico: kjespind@estud.usfq.edu.ec / kenny.josue@hotmail.com ORCID iD: https://orcid.org/0000-0003-4071-3542
} 


\section{RESUMEN}

El peculado es uno de los delitos más controvertidos en el ámbito del Derecho Penal ecuatoriano. Se encuentra tipificado en el Art. 278 del Código Orgánico Integral Penal, su relevancia se encuentra fundamentalmente en dos aspectos: la calidad del sujeto activo y el bien jurídico que protege. Para estudiar el tema materia de este artículo, primero es necesario definir otros conceptos que son de suma importancia para la comprensión de este trabajo, tales son el sujeto activo calificado, la autoría, coautoría, cómplices y la comunicabilidad de las circunstancias. Esto permitirá entender que, a pesar de que se exige cierta calidad al sujeto activo para ser considerado autor del delito de peculado, no se puede dejar sin castigo o con una pena menor a la persona que, sin la calificación exigida por el tipo, interviene con actos principales para su consumación. Sin embargo, la complejidad del tema lleva a que sea necesario observar dos figuras de suma relevancia que son: el intraneus y extraneus. Ambas contribuirán a la profundización del análisis que, en conjunto con el sustento de la jurisprudencia ecuatoriana, justificarán la relevancia que tiene el tema expuesto. Por lo que en el desarrollo de este ensayo se expondrán los diferentes criterios jurisprudenciales utilizados por las diferentes cortes y tribunales ecuatorianos para condenar al privado como coautor del delito de peculado, a pesar de no tener la calificación requerida por el ilícito.

\section{Palabras clave}

Sujeto activo calificado; autor; coautor; administración pública; peculado; intraneus; extraneus; Código Orgánico Integral Penal

\section{Abstract}

Embezzlement of official property by a public official is one of the most controversial crimes in the field of Ecuadorian Criminal Law. It is typified in Article 278 of the Organic Criminal Code and its relevance is fundamentally in two aspects: quality of the active subject and the legal asset that it protects. In order to assess the subject of this article, it is first necessary to define other concepts that are of utmost importance to understand this essay such as: qualified active subject, perpetrator, joint perpetrator, accomplices and the communicability of the circumstances. This will allow us to comprehend that, although a certain quality is required from the perpetrator to be considered an author, the person without the qualification required by the type, who sometimes intervenes with essential acts for its consummation, cannot be left unpunished or with a lesser penalty. However, the complexity of the subject makes it necessary to observe two highly relevant figures: the intraneus and extraneus. Both will contribute to the deepening of the analysis which, together with the support of the Ecuadorian jurisprudence, will justify the relevance of the exposed subject. Therefore, throughout this essay the different jurisprudential criteria used by the different Ecuadorian courts and tribunals to convict the pri- 
vate party as co-perpetrator of the crime of embezzlement despite not having the qualification required by the crime, will be exposed.

\section{KEYWORDS}

Perpetrator with special characteristics; perpetrator; joint perpetrator; public administration; embezzlement of official property by a public official; intraneus; extraneus; Organic Criminal Code.

\section{INTRODUCCIÓN}

Desde el 1 de marzo hasta el 31 de agosto del 2020, las noticias de delitos que llegan a fiscalía o aquellas investigaciones que se inician de oficio sobre el delito de peculado, tuvieron un incremento del $25.1 \%$ con respecto al período comprendido entre septiembre del 2019 y febrero del 2020. ${ }^{1}$ Esto demuestra que la comisión del delito de peculado se ha incrementado en el Ecuador. Lo cual, sin duda alguna, trae enormes efectos negativos en la sociedad ecuatoriana.

La Comisión Interamericana de Derechos Humanos (CIDH) en su resolución 1/18 sobre corrupción y Derechos Humanos, señala que: "La [l]a corrupción en la gestión de los recursos públicos compromete la capacidad de los gobiernos para cumplir con sus obligaciones de derechos sociales" 2 y afecta: "en particular a las poblaciones y grupos en condición de mayor vulnerabilidad". Por lo anterior, la lucha contra la corrupción es uno de los objetivos más importantes que deben tener en cuenta los gobiernos en el presente, pues esta no solo afecta a las arcas del Estado, sino que tiene una repercusión directa sobre los derechos de los ciudadanos.

El delito de peculado es una de las varias formas en las que se comete corrupción. En este delito no solo intervienen funcionarios públicos, sino que muchas veces, para su realización, es necesaria la intervención de sujetos privados que no ostentan la calidad de funcionario oficial. Por esta razón, la lucha contra la corrupción no debe ser dirigida únicamente contra los funcionarios públicos, sino que esta debe ampliarse hacia los sujetos privados que intervienen y facilitan la comisión de este tipo de ilícitos. Pero no es tan simple, pues existe una discusión respecto a la intervención de los sujetos que no ostentan la calificación exigida por el tipo penal de peculado, en la ejecución del ilícito. Esto se debe a que el peculado, al ser un delito de sujeto activo calificado, en

1 Mario Alexis González, "Peculado y concusión entre los delitos que crecieron durante la pandemia”. Primicias, 2020. https://www.primicias.ec/noticias/politica/corrupcion-delitos-aumenta-emergencia/

2 Resolución 1/18 Corrupción y Derechos Humanos, Comisión Interamericana de Derechos Humanos, 2 de marzo de 2018, 6 .

3 Ibid. 
principio restringe la comisión de este a los funcionarios públicos. Sin embargo, el no condenar como coautores o condenarlos como simples cómplices, sería dejar en la impunidad a los sujetos privados que participan de manera principal y directa en la comisión del peculado.

Las diferentes cortes y tribunales de nuestro país, en su mayoría, han determinado que los sujetos privados que contribuyen de manera principal en la comisión del delito de peculado sí pueden responder y ser condenados como coautores de este. No obstante, los argumentos y las teorías que usan para justificar estas decisiones varían entre sí, por lo que es necesario realizar un análisis sobre estas y determinar si son o no adecuadas las decisiones que han adoptado.

\section{El SUJETO ACTIVO Y EL PASIVO}

En primer lugar, es importante distinguir el concepto de sujeto y el de autor, dentro del ámbito penal. El primero tiene que ver con las personas que efectivamente concurren en la comisión de un delito, sea de manera activa o pasiva. ${ }^{4}$ Por otro lado, el segundo concepto hace referencia al grado y calidad de participación de esas personas en la comisión del delito. ${ }^{5}$ A pesar de que ambos conceptos están sumamente relacionados, cada uno tiene fines distintos dentro de la teoría del delito. Se puede afirmar que tienen un orden cronológico, en cuanto a que primero se deben determinar los sujetos que intervienen en la comisión y luego su grado de participación en el delito.

Una vez explicada la diferencia entre ambos conceptos, es necesario analizar a profundidad los conceptos de sujeto activo, sujeto pasivo y la relación intrínseca que tienen en los distintos tipos penales. Al respecto, Díaz-Aranda menciona que:

El sujeto activo es aquel que realiza la conducta que normativamente se considera como prohibida, sea de acción o de omisión, mientras que el sujeto pasivo es aquella persona o ente cuyo bien jurídico protegido fundamental ha sido lesionado o puesto en peligro con el comportamiento del sujeto activo. ${ }^{6}$

Al respecto, la doctrina nacional también se ha encargado de definir estas figuras, permitiendo una mayor comprensión. Ernesto Albán trata de manera más técnica ambas figuras y define al sujeto activo como: "[...] el agente que ejecuta el acto delictivo y que debe, en consecuencia, sufrir la pena corres-

4 Ernesto Albán Gómez, Manual de Derecho Penal Ecuatoriano Parte General (Quito: Ediciones Legales, 2018), 108-109.

5 Felipe Rodríguez Moreno, Curso de Derecho Penal Parte General Tomo II Teoría del Delito (Quito: Editorial Cevallos, 2019), 240-241.

6 Enrique Díaz-Aranda, Lecciones de Derecho Penal para el Nuevo Sistema de Justicia en México (Ciudad de México: Instituto de Investigaciones Jurídicas UNAM, 2014), 46. 
pondiente". ${ }^{7}$ Además, agrega otros factores importantes a tomar en cuenta como que el agente puede ser uno o varios individuos, también en qué forma y grado participa en la realización del delito y que en el ámbito del proceso penal este es el imputado. ${ }^{8}$ Esto nos permite ver la especial importancia que tiene esta figura dentro del derecho penal sustantivo, ya que incluso muchos tipos penales -como en los denominados delitos especiales- es determinante la calidad del sujeto activo. Por otro lado, respecto al sujeto pasivo es necesario mencionar que no se debe asociar siempre con la víctima, porque puede ser que en ocasiones este concepto no coincida con el del sujeto pasivo. ${ }^{9}$ Respecto a esta última figura, no existe mayor dificultad en su identificación o determinación en el delito; como quedó evidenciado anteriormente, el sujeto pasivo es el titular del bien jurídico protegido por el tipo penal.

\section{Sujeto activo Calificado}

Como se mencionó en el párrafo precedente, existen ciertos delitos denominados delitos cualificados o especiales, en los que el tipo exige que el sujeto activo sea calificado. Por sujeto activo calificado se debe entender que son aquellos: "sujetos revestidos de una especial cualidad fundante que les identifica y distingue de los demás". ${ }^{10}$ Lo que particulariza a esta figura es que el sujeto activo debe tener las características determinadas por el tipo penal por lo que, en principio, no cualquier persona puede cometerlo.

\section{CONCEPTOS DE AUTOR DiRECTO, COAUTORÍA Y CÓMPLiCe}

\subsection{AutOR DIRECTO}

El primer concepto por determinar, para efectos de este trabajo, es el de autor directo. El Código Orgánico Integral Penal (en adelante COIP) define al autor directo como aquel que comete: "la infracción de una manera directa e inmediata". ${ }^{11}$ La definición que provee el legislador ecuatoriano es insuficiente, pero es necesario tomarla en cuenta. Entonces, autor directo sería quien ejecute la totalidad de los elementos del tipo penal. Zaffaroni señala que es el "ejecutor" ${ }^{12}$ y quien tiene el "dominio de la acción". ${ }^{13}$ Una definición más clara de autor directo es la que provee Roxin, quien señala que: "es quien domina el acontecer que conduce a la realización del delito". ${ }^{14}$ Es decir que el

\footnotetext{
Ernesto Albán, Manual de Derecho Penal Ecuatoriano Parte General, 108.

Para más información, ver Ernesto Albán, Manual de Derecho Penal Ecuatoriano Parte General, 108.

Para más información, ver Ernesto Albán, Manual de Derecho Penal Ecuatoriano Parte General, 109.

Miguel Polaino Navarrete, Lecciones de Derecho Penal. Parte General, Tomo II (Madrid: Editorial Tecnos, 2013), 31.

Artículo 42, Código Orgánico Integral Penal [COIP], R.O. Suplemento 180 de 10 de febrero de 2014.

2 Eugenio Raúl Zaffaroni, Manual de Derecho Penal Parte General Segunda Edición (Buenos Aires: EDIAR, 2002), 777.

13 Ibid.

14 Claus Roxin, Derecho Penal Parte General Tomo II (Madrid: CIVITAS, 2014), 69.
} 
autor directo es quien tiene el dominio del curso causal y ejecuta la totalidad del delito por sí mismo.

\subsection{Coautoría}

Existen dos tipos de coautoría, la paralela y la: "caracterizada por el dominio funcional del hecho". ${ }^{15}$ En este caso únicamente se definirá la coautoría funcional. La coautoría funcional consiste en la "división de tareas" ${ }^{16}$ en la fase de ejecución del delito. A diferencia de lo que ocurre con la autoría directa, en la coautoría el delito: "se produce por la sumatoria de los actos parciales de todos los intervinientes". ${ }^{17}$ Es decir que en la coautoría son varios los sujetos intervinientes que aportan de manera principal a la ejecución del ilícito. Zaffaroni menciona que existen dos elementos de la coautoría. El elemento subjetivo, el cual es: "la decisión común al hecho"18 y el elemento objetivo que: "es la ejecución de esta decisión mediante división del trabajo". ${ }^{19}$

Este concepto se encuentra tipificado en el artículo 42 numeral 3 del COIP, el cual señala que son coautores: “"[q]uienes coadyuven a la ejecución, de un modo principal, practicando deliberada e intencionalmente algún acto sin el cual no habría podido perpetrarse la infracción" ${ }^{20}$ La definición del COIP es muy acertada pues, para que exista coautoría, es necesario que la división del trabajo se realice en la fase ejecutiva del delito (no en la preparatoria ${ }^{21}$ y que los actos realizados por el coautor sean principales. Es decir que sin ellos no se hubiese podido realizar el delito.

\subsection{Cómplice}

El COIP tipifica en el artículo 43 que: "responderán como cómplices las personas que, en forma dolosa, faciliten o cooperen con actos secundarios, anteriores o simultáneos a la ejecución de una infracción penal, de tal forma que, aun sin esos actos, la infracción se habría cometido". ${ }^{22}$ Con esta definición que brinda el Código, queda claro que los cómplices son aquellas personas que ayudan a que el injusto se ejecute. La relevancia se encuentra en que los actos cooperativos que realizan son secundarios, a diferencia del coautor (que ejecuta actos principales). El coautor funcional es necesario para la ejecución de la infracción pues ejecuta una parte de la totalidad de la infracción. En

15 Zaffaroni, Derecho Penal, 785.

16 Ibid.

17 Ibid.

18 Ibid.

19 Ibid.

20 Artículo 42 numeral 3, COIP.

21 Ver, Claus Roxin, Derecho Penal, 151.

22 Artículo 43, COIP. 
cambio, los cómplices facilitan el cometimiento del ilícito, mas no influyen de manera directa en el mismo y, por lo tanto, si fuesen sacados de escena, el ilícito igual se cometería.

\section{LOS DELITOS CONTRA LA EFICIENCIA DE LA ADMINISTRACIÓN PÚBLICA}

En Ecuador, el Capítulo Quinto del COIP denominado "Delitos contra la responsabilidad ciudadana" tipifica, en su sección tercera, a los delitos contra la eficiencia de la administración pública, desde el Art. 278 hasta el Art. 294. La Constitución de la República del Ecuador (en adelante CRE), en su Art. 227, sostiene que: "la administración pública constituye un servicio a la colectividad que se rige por los principios de eficacia, eficiencia, calidad, jerarquía, desconcentración, descentralización, coordinación, participación, planificación, transparencia y evaluación”. ${ }^{23}$ Este servicio lo ejecuta el Estado a través de los servidores públicos, quienes deben ejercer con sujeción a los principios que menciona el artículo citado. En este sentido, unos artículos más adelante, en el segundo inciso del artículo 233 se establece que:

Las servidoras o servidores públicos y los delegados o representantes a los cuerpos colegiados de las instituciones del Estado estarán sujetos a las sanciones establecidas por delitos de peculado, cohecho, concusión y enriquecimiento ilícito. La acción para perseguirlos y las penas correspondientes serán imprescriptibles y en estos casos, los juicios se iniciarán y continuarán incluso en ausencia de las personas acusadas. Estas normas también se aplicarán a quienes participen en estos delitos, aun cuando no tengan las calidades antes señaladas (énfasis ańadido). ${ }^{24}$

Este artículo es esencial para el presente análisis. En el inciso anterior existen varios temas que vale la pena analizar brevemente. En primer lugar, la última frase es la base de la cual se parte para realizar el estudio jurídico y sostener una determinada posición frente a un tema en el cual existen diversos criterios. A lo largo de los años, se ha discutido en muchos Estados el grado de participación que debe tener el extraneus en este tipo de delitos. En Ecuador, los criterios jurisprudenciales han variado, otorgando distintos niveles de participación al interviniente que no posee la calificación requerida por el tipo. Por otro lado, este inciso también prescribe el juzgamiento en ausencia, un tema que ha sido motivo de una abundante discusión jurídica, pero que por las características del presente trabajo no será analizado.

Corresponde definir qué se debe entender por delitos contra la eficiencia de la administración pública. Podemos definir a estos delitos como conductas

23 Artículo 277, Constitución de la República del Ecuador, R.O. Suplemento 449, de 20 de octubre de 2008.

24 Artículo 233, Constitución de la República del Ecuador, 2008. 
que lesionan el: “[...] poder público que tiene a su cargo la obligación de velar por los intereses generales, conservar el orden, proteger el Derecho y facilitar el desenvolvimiento de las actividades lícitas". ${ }^{25}$ La existencia de este tipo de delitos muestra la estrecha relación que tiene el Derecho Penal con otras ramas, como el Derecho Administrativo. En estos injustos se puede distinguir e individualizar a los elementos del tipo en donde existirán: un sujeto activo calificado (intraneus y extraneus), el verbo rector (variará dependiendo del tipo que se trate), el sujeto pasivo (el Estado), el elemento subjetivo (doloso), el objeto material (dependerá de cada delito) y el bien jurídico protegido.

El sujeto activo calificado, y su división en el intraneus y extraneus, se analizará más adelante a detalle. En cuanto al verbo rector, como se mencionó en su oportunidad, este va a variar dependiendo del delito que se trate. Sobre el sujeto pasivo no existe discusión alguna, ya que en estos delitos quien resulta afectado de manera directa es el Estado. Finalmente, en este punto es importante entrar a analizar el bien jurídico que se protege.

Los bienes jurídicos protegidos pueden ser definidos como aquellos "intereses, individuales o sociales" ${ }^{26}$ que merecen una protección por su trascendencia en el bienestar común de una sociedad y el respeto de los derechos individuales. Son aquellos bienes que tienen una importante relevancia en la vida del ser humano y, por lo tanto, existe un interés de protegerlos. Como ejemplos de estos bienes se encuentran: la vida, la libertad, la propiedad o la eficiencia de la administración pública.

La doctrina es uniforme al considerar que el bien jurídico común que se desea proteger en este tipo de delitos es la correcta y eficiente administración pública. Así, Rafael H. Chanjan sostiene que: "[l]os delitos contra la administración pública protegen un bien jurídico institucional denominado 'correcto funcionamiento de la administración pública' $[\ldots]$ no se protege a los órganos administrativos como tales, sino a la función pública $[\ldots]$ ”. ${ }^{27}$ La doctrina italiana señala que el bien jurídico protegido en este tipo de delitos: "es el regular desenvolvimiento de las funciones públicas estatales, esto es, que el Estado pueda desarrollar, sin alteraciones, sus actividades $[\ldots] "{ }^{28}$ Es importante mencionar que cada injusto penal tiene su propio bien jurídico protegido concreto. Lo que busca la doctrina es desarrollar una definición integradora.

25 Edgardo Alberto Donna, Derecho Penal Parte Esepcial Tomo III, (Buenos Aires: Rubinzal - Culzoni Editores, 2000), 26.

26 Albán, Manual de Derecho Penal Ecuatoriano Parte General, 19.

27 Rafael H. Chanjan Documet, "El correcto Funcionamiento de la administración pública: Fundamento de incriminación de los delitos vinculados a la corrupción pública", Revista Derecho Penal y Criminología Vol. 38, no. 104 (enero - junio 2017): 137, https://revistas.uexternado.edu.co/index.php/derpen/article/view/5210/6277.

28 Edgardo Alberto Donna, Derecho Penal Parte Esepcial Tomo III, 27. 


\section{Peculado}

Uno de los delitos más comunes y relevantes dentro de los ilícitos en contra de la administración pública es el peculado. Guillermo Cabanellas define al peculado como la: "sustracción, apropiación o aplicación indebida de los fondos públicos por aquel a quien está confiada su custodia o administración". ${ }^{29}$ Para Cueva Carrión, el delito de peculado consistente en: "faltar a la fidelidad que todo servidor público tiene para con los bienes que están a su cargo y responsabilidad". ${ }^{30}$ A partir de las definiciones expuestas se desprende que un aspecto esencial de este delito es que el funcionario público decide obrar contrario a su deber de velar por los bienes que le han sido confiados.

En Ecuador este delito se encuentra tipificado en el artículo 278 del COIP y es uno de los más extensos. Para el propósito del presente trabajo, se ha puesto énfasis en analizar el primer inciso del delito, el cual prescribe:

Art. 278.- Peculado.- Las o los servidores públicos y las personas que actúen en virtud de una potestad estatal en alguna de las instituciones del Estado, determinadas en la Constitución de la República, en beneficio propio o de terceros; abusen, se apropien, distraigan o dispongan arbitrariamente de bienes muebles o inmuebles, dineros públicos o privados, efectos que los representen, piezas, títulos o documentos que estén en su poder en virtud o razón de su cargo, serán sancionados con pena privativa de libertad de diez a trece ańos. [...]. ${ }^{31}$

El delito de peculado, en palabras sencillas, es aquella conducta ilícita en la que el funcionario público, arbitrariamente, decide utilizar de manera ilegítima dineros o bienes públicos para obtener un beneficio propio o de terceros.

Un elemento trascendental del tipo de peculado es el beneficio propio o de terceros que se obtiene a partir de la realización de la conducta ilícita. $\mathrm{Si}$ no existe el aprovechamiento o beneficio patrimonial del sujeto que realiza la conducta delictiva o de un tercero, la conducta sería atípica y no existiría peculado.

29 Guillermo Cabanellas de Torres, Diccionario Jurídico Elemental (Buenos Aires: Editorial Heliasta, 2006), 355.

30 Luis Cueva Carrión, Peculado Tomo I: Teoría, práctica y jurisprudencia. (Quito: Ediciones Cueva Carrión. Kindle Edition, 2006), 1640.

31 Artículo 278, COIP. 


\section{Criterios Jurisprudenciales Para DETERMinar la COAUTORÍA DE PERSONAS SIN LA CALIFICACIÓN DE FUNCIONARIO PÚBLICO}

En los distintos casos resueltos por los tribunales de primera instancia, apelación o casación, existen diferentes argumentos o criterios que han sido utilizados para condenar como autores del delito de peculado a personas que no tienen la calidad de funcionario público. En los siguientes subtítulos se analizarán aquellos criterios que se consideran relevantes para efectos del tema.

\subsection{El artículo 233 de la Constitución de la República DEL ECUADOR}

En diferentes ocasiones, los tribunales han sustentado la autoría de personas privadas que no tienen la calificación de funcionario público, argumentando que el artículo 233 de la $\mathrm{CRE}^{32}$ extiende la responsabilidad a los privados y permite que sean condenados por estos delitos en calidad de coautores.

El uso del artículo 233 de la CRE como argumento para fundamentar la punición de privados en su calidad de coautores, se evidencia en el proceso número 17294-2018-00704, tanto en la sentencia de primera instancia como en la sentencia de apelación emitida por la Corte Provincial. Este es un proceso seguido a un grupo de funcionarios públicos del Instituto Ecuatoriano de Seguridad Social (de ahora en adelante IESS) y a un privado por un supuesto peculado por la compra de insumos médicos con sobreprecios. Es importante señalar que, si bien las sentencias a ser analizadas no constituyen un precedente jurisprudencial obligatorio, son decisiones que contienen un análisis jurídico útil para el tema objeto de este ensayo.

Para efectos del presente análisis, se examinará únicamente la situación jurídica del procesado que no tiene la calidad de funcionario público, quien en primera instancia fue condenado como autor del delito de peculado ${ }^{33}$, tipificado en el cuarto artículo innumerado agregado a continuación del artículo

32 Art. 233.- Ninguna servidora ni servidor público estará exento de responsabilidades por los actos realizados en el ejercicio de sus funciones o por omisiones, y serán responsable administrativa, civil y penalmente por el manejo y administración de fondos, bienes o recursos públicos.

Las servidoras o servidores públicos y los delegados o representantes a los cuerpos colegiados a las instituciones del Estado, estarán sujetos a las sanciones establecidas por delitos de peculado, cohecho, concusión y enriquecimiento ilícito. La acción para perseguirlos y las penas correspondientes serán imprescriptibles y en estos casos, los juicios se iniciarán y continuarán incluso en ausencia de las personas acusadas. Estas normas también se aplicarán a quienes participen en estos delitos, aun cuando no tengan las calidades antes señaladas.

33 Ver Causa No. 17294-2018-00704, Tribunal de Garantías Penales de Pichincha, 19 de noviembre del 2019. 
$257^{34}$ del Código Penal (vigente al momento en que se cometió el delito). ${ }^{35}$ En segunda instancia ${ }^{36}$, el privado fue condenado como coautor del delito de peculado, tipificado en el artículo 257 inciso primero del Código Penal ${ }^{37}$, actual artículo 278 inciso primero del COIP. ${ }^{38}$

En primera instancia el tribunal de Garantías Penales de Pichincha, como ya se mencionó, condenó al privado, representante legal de la empresa que contrató con el IESS, en calidad de autor del delito de peculado por la venta con sobreprecio de equipos médicos. En la sentencia emitida por el Tribunal, al momento de analizar los elementos de la tipicidad objetiva del delito, con respecto al representante legal de la empresa, se señala que el sujeto privado favorecido por la contratación realizada en contra de disposiciones legales puede responder como autor calificado de conformidad con el artículo 233 de la CRE. Específicamente, el Tribunal argumenta que el artículo mencionado:

[...] permite en este tipo de delitos extender la responsabilidad a particulares, doctrinariamente identificados como extraneus, pese a que el sujeto activo propio del tipo de peculado es el funcionario público intraneus, es decir quien comete "una infracción de deber positivo" respecto del bien jurídico cuidado y manejo de bienes y fondos públicos, permitiéndose que el extraneus se convierta "en un autor calificado por cuanto se encuentra en una relación especial con el bien jurídico protegido, al mismo que solo tienen acceso ciertas personas habilitadas "relación de dominio" por la posición que detentan $[\ldots] .{ }^{39}$

Como es evidente, el Tribunal ha interpretado que el artículo 233 de la CRE, al prescribir que: "[e]stas normas también se aplicarán a quienes participen en estos delitos, aun cuando no tengan las calidades antes señaladas", permi-

34 Art. 257-C.- La misma pena señalada en los artículos anteriores se impondrá a las personas elegidas por votación popular, a los representantes o delegados y a los funcionarios, empleados o servidores públicos que aprovechándose de la representación popular o del cargo que ejercen se favorezcan o hayan favorecido a personas naturales o jurídicas para que, en contra de expresas disposiciones legales o reglamentarias, les hubiesen concedido contratos o permitido la realización de negocios con el Estado o con cualquier otro organismo del sector público.

35 Conducta que ahora se encuentra tipificada como tráfico de influencias en el artículo 285 inciso segundo del COIP Art. 285.- El máximo de la pena prevista será aplicable cuando las personas descritas en el primer inciso, aprovechándose de la representación popular o del cargo que ejercen, se favorezcan o hayan favorecido a personas naturales o jurídicas para que, en contra de expresas disposiciones legales o reglamentarias, les concedan contratos o permitan la realización de negocios con el Estado o con cualquier otro organismo del sector público

36 Ver Causa No. 17294-2018-00704, Corte Provincial de Pichincha, Sala Especializada de lo Penal, Penal Militar, Penal Policial y Tránsito, 21 de agosto de 2020.

37 Art. 257.- Serán reprimidos con reclusión mayor ordinaria de ocho a doce ańos, los servidores de los organismos y entidades del sector público y toda persona encargada de un servicio público, que, en beneficio propio o de terceros, hubiere abusado de dineros públicos o privados, de efectos que los representen, piezas, títulos, documentos, bienes muebles o inmuebles que estuvieren en su poder en virtud o razón de su cargo, ya consista el abuso en desfalco, disposición arbitraria o cualquier otra forma semejante. La pena será de reclusión mayor extraordinaria de doce a dieciséis ańos si la infracción se refiere a fondos destinados a la defensa nacional.

38 Art. 278.- Las o los servidores públicos y las personas que actúen en virtud de una potestad estatal en alguna de las instituciones del Estado, determinadas en la Constitución de la República, en beneficio propio o de terceros; abusen, se apropien, distraigan o dispongan arbitrariamente de bienes muebles o inmuebles, dineros públicos o privados, efectos que los representen, piezas, títulos o documentos que estén en su poder en virtud o razón de su cargo, serán sancionados con pena privativa de libertad de diez a trece ańos.

39 Causa No. 17294-2018-00704, Tribunal de Garantías Penales de Pichincha, 19 de noviembre del 2019 
te que la extensión de esta responsabilidad implica que terceros puedan ser condenados como autores de este tipo de delitos, aun cuando no detentan la calidad de funcionario público. Esta es una interpretación cuestionable, pues a través de un análisis diferente podría decirse que el artículo 233 de la CRE no está diciendo que los privados pueden responder como autores, sino únicamente que las reglas de imprescriptibilidad de la pena y acción penal en conjunto con la posibilidad de ser juzgados en ausencia son aplicables a las personas privadas que han participado (podría ser como cómplice), en la comisión del delito.

Sin embargo, no viene al caso realizar una crítica a la interpretación del artículo realizada por el Tribunal. Lo que atańe es entender que el Tribunal utiliza como argumento al artículo 233 de la CRE para concluir que esta norma permite que el privado se convierta en un "autor calificado" 40 , y por lo tanto pueda ser sentenciado como autor del delito de peculado. Respecto a esto, dentro del mismo proceso, en la sentencia de segunda instancia el Tribunal de alzada (donde se sentenció por el inciso primero del artículo 257 del CP) señaló que:

Por ello, el legislador -con la finalidad de no dejar impunes las conductas de los extraneus- consideró pertinente su inclusión en la CRE, permitiendo la intervención del derecho penal en las esferas de libertad de los particulares que participan en la comisión de delitos especiales, estableciendo la obligación de que todo ciudadano si no quiere ver restringido su ámbito de libertad, tiene la obligación de no dańar los bienes jurídicos tutelados por el Derecho penal, en este caso, la "eficiente administración pública” ${ }^{41}$

En este caso, en una línea de argumentación similar, pero con un mayor análisis, la Corte Provincial de Pichincha ha señalado que para evitar la impunidad de los sujetos privados que no cuentan con la calificación de funcionario público, a través del artículo 233, se permite que sean condenados por este tipo de delitos. De acuerdo con la Corte, esto se debe a que los privados tienen el deber de no lesionar el bien jurídico de la eficiente administración pública. Además, la Corte Provincial señala que en el caso presente los infractores han actuado:

[...] con actos principales y decisivos para la consumación de la infracción, unificando el pensamiento y la resolución punibles en la realización de hechos ligados íntimamente con la infracción y que han llevado a la ejecución, estableciéndose entre ellos un vínculo solidario frente al propósito de delinquir y causar los daños sancionados por la norma penal. En definitiva, se los reputa coautores por haber coadyuvado a la ejecución de un modo principal, practicando deliberada e intencionalmente algún acto sin el cual no habría podido perpetrarse la infracción. ${ }^{42}$

\footnotetext{
40 Ibid.

41 Causa No. 17294-2018-00704, Corte Provincial de Pichincha, Sala Especializada de lo Penal, Penal Militar, Penal Policial y Tránsito, 21 de agosto de 2020, párr. 91.

42 Id., párr. 90.
} 
Con base en la cita precedente, la Corte ha determinado que el sujeto privado, que no detenta la calificación de funcionario público, responde como coautor del delito en vista de que ha cooperado de manera principal en la ejecución del mismo. En el caso específico, el privado ha proporcionado los insumos médicos con sobreprecio al IESS, siendo esto una parte esencial para la consumación del peculado.

Adicionalmente, dentro del proceso No. 17721-2017-00204, en el cual la Corte Nacional de Justica condenó como cómplice por el delito de concusión a un sujeto privado, se señaló que:

[...] desde el año 2008, la CRE en su artículo 233, establece que terceros que participan en los delitos de peculado, cohecho, concusión y enriquecimiento ilícito, sin contar con la calidad de servidores públicos, también pueden ser juzgados por el cometimiento de tales injustos penales, lo cual, en doctrina se conoce como la participación del extraneus, esto es cuando un tercero, participa en un delito especial, como el que se juzga en el presente caso, por tanto, el procesado John Pólit Esteves, bajo las circunstancias jurídicas descritas, también cumple con la calidad de sujeto activo del delito de concusión. ${ }^{43}$

En este caso, John Pólit Esteves no tenía la calificación de funcionario público y la Corte consideró que "cooperó simultáneamente en las 'exigencias' del dinero" ${ }^{44}$ y por lo tanto fue condenado como cómplice. Sin embargo, lo relevante de esta sentencia es que la Corte establece que la Constitución del 2008, en su artículo 233, amplifica la tipicidad de los delitos contenidos en dicho artículo, y la extiende hacia los sujetos privados que participan sin tener la calidad de funcionarios públicos. Entonces, se utiliza al artículo mencionado como argumento para determinar que los privados sí pueden ser sujetos activos de dichos delitos, y por lo tanto pueden responder como autores, coautores o cómplices, dependiendo de su grado de participación.

En la resolución de un recurso de casación dentro de la causa 414B-2010 (peculado bancario), conocido como el caso Filanbanco, la Corte Nacional de Justica, de manera similar a las sentencias ya citadas, expuso que:

En el caso de los delitos especiales, como ya se observó, el sujeto activo debe reunir ciertas calidades específicas, mas puede darse el caso de que participen en la ejecución del hecho punible personas que no reúnen tales calidades -empleados públicos-, que en el caso del Ecuador, por las Constituciones de 1998 y 2008, por el acto ejecutado, también lo puede ser una persona particular, conforme está determinado también en la norma. ${ }^{45}$

43 Causa No. 17721201700204, Tribunal de Garantías Penales, Sala Especializada de lo Penal, Penal Militar, Penal Policial y Tránsito de la Corte Nacional de Justicia, 20 de julio del 2018.

44 Ibid.

45 Causa No. 414B-2010, Corte Nacional de Justicia, Sala Especializada de lo Penal, Penal Militar, Penal Policial y Tránsito 
Una vez más, se observa como la Corte Nacional de Justica optó por determinar que la Constitución del 2008 permite que los sujetos que no detentan la calidad de funcionario público también pueden responder por el delito de peculado y, dependiendo de su grado de participación, podrían ser condenados como coautores de este.

Como se ha evidenciado a través de las sentencias citadas, el criterio jurisprudencial en el Ecuador ha estado dirigido a aceptar que los sujetos que intervienen en la comisión de peculado y que no tienen la calidad de funcionario público, sí pueden responder por el delito de peculado con base en lo prescrito por el artículo 233 de la Constitución.

Sin embargo, esta línea argumentativa ha sido objeto de algunas críticas. Por ejemplo, Jorge Zavala Egas, sobre la interpretación del artículo 233 de la CRE y la amplificación de la tipicidad, señala que:

[...] es una interpretación carente de toda racionalidad jurídica. Es obvio que la norma constitucional se limitó a agravar la pena de los extranei, autores del delito común paralelo, equiparándola a la de los intranei, autores de esos delitos especiales, pero no convirtió a aquellos en «autores» de los mismos. ${ }^{46}$

Es importante tomar en cuenta un punto de vista contrario y crítico respecto a las líneas argumentativas que fueron expuestas. Como se observa, Zavala Egas critica la interpretación del artículo que amplifica la tipicidad del peculado y la extiende a los sujetos privados. Según él, el artículo 233 de la CRE únicamente se ha limitado a extender las reglas de imprescriptibilidad, juzgamiento en ausencia y las penas a los sujetos privados. Pero, de acuerdo con su criterio, la norma: "[...] no autoriza que los particulares sean imputados a título de autores de los delitos de peculado [...]". ${ }^{47}$ A pesar de que la posición expuesta es sumamente interesante, esta implica la divisibilidad de la infracción penal y la aplicación de la pena del delito especial para el sujeto privado. Algo que no queda claro cómo funcionaría y podría acarrear ciertos problemas en la imputación.

\subsection{APLICACIÓN DE LA FIGURA DEL INTRANEUS Y EL EXTRANEUS}

Como se observa en las citas tomadas de la sentencia de primera instancia dentro del proceso No. 17294-2018-00704, el Tribunal habla de la figura del intraneus y extraneus. Es importante realizar un análisis más profundo del

de la Corte Nacional de Justicia, 29 de octubre de 2014, pág. 60.

46 Jorge Zavala Egas, Peculado general y bancario de un precedente jurisprudencial a un estudio dogmático del COIP (Guayaquil: Murillo Editores, 2015), 146.

47 Jorge Zavala Egas, Peculado general y bancario, 138. 
uso de estos términos para entender de mejor manera cómo el sujeto que no detenta la calidad requerida por el tipo penal puede responder como autor del delito de peculado.

Al respecto, el tratadista Felipe Rodríguez, en su libro Curso de Derecho Penal Parte General Tomo II, señala que, por regla general, si el autor no ostenta la calidad requerida por tipo penal, en este caso sería la de funcionario público, "no puede cometer el delito concreto". ${ }^{48}$ Sin embargo, existen las ya mencionadas figuras del intraneus y extraneus. Rodríguez determina que: "intraneus es el sujeto calificado per se"39, pero para poder hablar del intraneus propiamente, debe existir en la comisión del delito la participación de un tercero: "que no es sujeto activo calificado y que, por lo mismo, no puede quedar exento de responsabilidad, pues fue partícipe necesario o coautor". ${ }^{50}$ Es importante acotar que, para la existencia del extraneus, es necesario que exista el sujeto activo calificado (intraneus), pero no viceversa; es decir que sí puede existir un intraneus sin la participación en los hechos de un extraneus. ${ }^{51}$ Por lo tanto, el extraneus sería: "el sujeto activo no calificado que participa en el grado de coautoría con el sujeto activo calificado y que por disposición normativa [...], responderá en la misma calidad y gravedad que el sujeto activo calificado" (énfasis añadido). ${ }^{52}$

Cuando el autor escribe que el extraneus responde únicamente cuando existe una disposición normativa, se refiere a que debe estar expresamente prevista en la ley la posibilidad de que el extraneus pueda responder en la misma calidad que el funcionario público. Específicamente en el delito de peculado, Rodríguez señala que esta disposición normativa sería la parte del tipo penal, tipificado en el vigente artículo 278 del COIP, el cual prescribe: "en beneficio propio o de terceros". ${ }^{33}$ En el artículo $257-\mathrm{C}$ del Código Penal, tipo por el cual fue sentenciado en primera instancia el representante de la empresa, se encuentra una disposición normativa similar, la cual señala que: "se favorezcan o hayan favorecido a personas naturales o jurídicas". ${ }^{54}$ De igual manera, encontramos disposiciones similares en el artículo 257 inciso primero del Código Penal, delito por el cual fue sentenciada la persona privada dentro del proceso analizado en segunda instancia; y en delito de tráfico de influencias en el artículo 285 inciso segundo del COIP.

Rodríguez explica en qué consisten las figuras de intraneus y extraneus, por lo que ahora compete entender su aplicación en la sentencia objeto de análisis.

48 Rodríguez, Curso de Derecho Penal Parte General, 225.

49 Ibid.

50 Ibid

51 Rodríguez, Curso de Derecho Penal Parte General, 227.

52 Ibid.

53 Ibid., 228

54 Artículo 257 C, Código Penal [CP], R.O. Suplemento 147, de 22 de enero de 1971, reformado por última vez R.O. Suplemento 180 de 10 de febrero de 2014. 
La Corte Provincial en el caso analizado, señala, respecto al intraneus y extraneus, que:

\begin{abstract}
Ambos ejecutan todos los actos necesarios para que la infracción pueda perpetrarse; el uno comienza la obra delictuosa y el otro la complementa, determinándose de acuerdo a su participación, distintos grados previstos en nuestro ordenamiento jurídico, sin embargo, todos responden por el delito de peculado. En este tipo de delitos se admite la participación del extraneus que no ostenta esa obligación especial. Por consiguiente, los procesados que no tienen la investidura de servidores públicos son partícipes del delito de peculado, todos contribuyen a ejecutar el acto y se aprovechan de su resultado para sí o para terceros, si el intraneus junto con el extraneus realizan actos idóneos que concluyen en el delito de peculado, lo lógico jurídicamente hablando es que respondan por sus conductas ilícitas. ${ }^{55}$
\end{abstract}

De acuerdo con la cita recopilada de la sentencia condenatoria emitida por la Corte Provincial, se observa cómo el tribunal determina que si el extraneus contribuye de manera principal en la ejecución de delito y recibe un beneficio de este, debe responder por las conductas que ha realizado. De igual manera, la Corte Nacional de Justicia, en la resolución del recurso de casación ya citado, ha señalado que: "por mandato constitucional, el extraneus se encuentra en igualdad de condiciones que el intraneus en lo que se refiere al cometimiento del delito de peculado, de acuerdo claro está, con su grado de participación" ${ }^{56}$ De igual forma, la Corte Nacional de Justicia, en la sentencia de primera instancia, dentro del proceso 17721-2019-00029G por cohecho, menciona que los sujetos privados tienen: "su calidad de 'extraneus' que les otorga lo prescrito por el artículo 233 de la CRE" ${ }^{57}$ Estas citas demuestran que la Corte Nacional también ha optado por considerar al sujeto privado como extraneus y que este sí puede responder como coautor de este tipo de delitos. En este sentido, la Corte señala que el privado se encuentra en una posición igual al funcionario público y que, en consecuencia, sí debe responder por el delito de peculado.

Lo que procede, una vez que se ha determinado que el extraneus sí puede participar de la comisión de un delito cualificado, es determinar su grado de participación. En el caso citado, la Corte Provincial ha determinado que existe:

[...] un concurso de infractores que actúan con actos principales y decisivos para la consumación de la infracción, unificando el pensamiento y la resolución punibles en la realización de hechos ligados íntimamente con la infracción y que han llevado a la ejecución, estableciéndose entre ellos un vínculo solidario frente al propósito de delinquir y causar los daños sancionados por la norma penal. En definitiva,

55 Causa No. 17294-2018-00704, Corte Provincial de Pichincha, párr. 90.

56 Causa No. 414B-2010, pág. 60.

57 Causa No. 17721-2019-00029G, Tribunal de Garantías Penales, Sala Especializada de lo Penal, Penal Militar, Penal Policial y Tránsito de la Corte Nacional de Justicia, 26 de abril de 2020, pág. 362. 
se los reputa coautores por haber coadyuvado a la ejecución de un modo principal, practicando deliberada e intencionalmente algún acto sin el cual no habría podido perpetrarse la infracción. ${ }^{58}$

Por lo tanto, acogiendo los acertados criterios del autor, la Corte Provincial y la Corte Nacional de Justicia; es perfectamente posible, con base en la figura del extraneus, que el privado que no detenta la calidad exigida por el tipo penal de peculado y ha realizado actos principales en la ejecución del tipo, responda en la misma calidad (coautor) que el funcionario público. Pues, carecería de lógica que el extraneus que ha realizado actuaciones indispensables para la comisión del ilícito y ha obtenido un beneficio de este, únicamente sea sentenciado, por ejemplo, como un cómplice, recibiendo una pena menor. Esto, evidentemente, dejaría en la impunidad la conducta del privado que carece de la calificación exigida por el tipo penal. Además, en los delitos que tienen lugar en el proceso analizado es evidente que el extraneus ha realizado una conducta sin la cual el delito no se hubiese consumado. Pues, en el caso mencionado, sin la participación del extraneus, hubiese sido imposible que la institución pública adquiera determinados insumos médicos con sobreprecio.

\subsection{LA COMUNICABILIDAD DE LAS CIRCUNSTANCIAS}

Un criterio distintivo utilizado en la jurisprudencia ecuatoriana para extender la responsabilidad penal de los particulares en el delito de peculado es la comunicabilidad de las circunstancias. Las circunstancias son aquellos "[..] accidentes, modalidades de tiempo, lugar, modo, condición, estado, edad, parentesco, salud y demás particularidades que acompañan a algún hecho o acto" ${ }^{59}$ En materia penal, las circunstancias cualifican a la conducta ilícita de tal manera que pueden agravarla o atenuarla. ${ }^{60}$ Estas serían, por ejemplo, la reincidencia, la calidad de cónyuge de uno de los autores, y la más relevante para efectos de este ensayo: la calidad de funcionario público. La interrogante que surge en la doctrina, con respecto a la comunicabilidad de las circunstancias en aquellos delitos que requieren la calidad de funcionario público, en específico el peculado, es si las circunstancias se comunican entre los intervinientes o no. Es decir que en el caso de la comisión de un peculado donde ha intervenido un funcionario público, pero además un particular: ¡el sujeto privado debe responder por peculado o por otro delito?

Para responder a esta interrogante, primero se debe determinar los dos tipos de circunstancias que existen. Ernesto Albán Gómez las ha dividido en personales y materiales. Las primeras "son las relativas al sujeto activo de la infracción:

58 Causa No. 17294-2018-00704, Corte Provincial de Pichincha, párr. 90.

59 Cabanellas de Torres, Diccionario Jurídico Elemental, 79.

60 Ibid. 
parentesco, calidad personal, función o profesión que desempeña, antecedentes, etc." ${ }^{11}$ Las segundas son aquellas "relativas al delito mismo, a la forma en que se lo ejecuta, a los medios empleados o a los modos", ${ }^{62}$ por ejemplo, ejecutar un delito con violencia o fuerza. Respecto a las circunstancias materiales, solo se comunican si estas son conocidas por el otro interviniente. ${ }^{63}$

La discrepancia en la doctrina surge respecto a las circunstancias personales que "el legislador ha incorporado a la tipicidad de ciertos delitos [...]" ${ }^{64}$ Estas serían, por ejemplo, la calidad de funcionario público en el delito de peculado. Cuando las circunstancias son incorporadas al tipo penal, como ocurre con el delito de peculado, "se han convertido de circunstancias personales en circunstancias materiales, propias del delito" ${ }^{65} \mathrm{y}$, por lo tanto, lo lógico sería que si son conocidas por el otro interviniente, es decir el particular (en el caso del peculado), sí se comuniquen. Como ya se conoce, este delito exige la calidad de funcionario público al sujeto activo. Pero, como se ha analizado anteriormente en el caso expuesto, puede ocurrir que en la comisión del ilícito intervenga un sujeto que no posee la calidad de funcionario público. Por lo tanto, si el particular que interviene en el delito conoce que el otro tiene la calidad de funcionario público, aquella circunstancia se deberá comunicar y, por lo tanto, el particular deberá responder por el mismo delito que el servidor público.

La jurisprudencia en Ecuador se ha inclinado mayormente por aceptar que las circunstancias personales recogidas en el tipo penal, como es la calidad de funcionario público, sí se deben comunicar entre los intervinientes. Esto se ve expuesto en una sentencia publicada en la Gaceta Judicial del año LXXXII Serie XIII No. 13. En esta sentencia el Tribunal señala que: "comprobada la infracción de uso arbitrario de fondos públicos, tanto los funcionarios o empleados del Estado, como aquellos que no lo son, pero que hayan participado en ella, responden por la misma" ${ }^{66}$ Este es un caso de peculado bancario, donde en principio el particular que no ostenta la calidad exigida por el tipo penal fue sentenciado como autor del delito de estafa y los intervinientes que sí poseen la calidad exigida respondieron por el delito de peculado. Sin embargo, respecto a lo citado, el Tribunal resolvió que la intervención del particular fue necesaria para la comisión del ilícito y, al cometer el peculado en coautoría con los sujetos calificados, el particular debe responder por el mismo delito.

En otra sentencia, publicada en la Gaceta Judicial del año LXXIX Serie XIII No. 5, el Tribunal Supremo de Justicia señala que: "el particular que concurre al peculado cometido por un funcionario público [...] responderá de pecula-

61 Albán, Manual de Derecho Penal Ecuatoriano Parte General, 256.
62 Ibid.
63 Ibid.
64 Ibid.
65 Ibid.
66 Gaceta Judicial Año LXXXII, Serie 13, No. 13, Quito, 7 de octubre de 1981, 3105. 
do" ${ }^{67} \mathrm{El}$ Tribunal justifica esto señalando que cuando el particular participa en el delito "lo quiere en su totalidad, es decir, como ente de hecho y como ente jurídico" ${ }^{68}$ De modo que, cuando el particular concurre en la comisión de peculado, el particular asume la comisión del ilícito y, por lo tanto, se deben comunicar las circunstancias. En este caso, aquella circunstancia que se refiere a la calidad de funcionario público. En esta sentencia, el Tribunal concluye que el particular debe responder por el mismo delito del cual responde el funcionario público, es decir peculado, porque la coautoría implica que no se debe dividir la infracción penal. ${ }^{69}$

En la resolución de un recurso de casación, en 2004, dentro del juicio penal Nro. 3-03, los privados argumentan que el juzgamiento hecho a ellos por el delito de peculado es ilegal debido a que ellos no son funcionarios públicos. La Corte Suprema de Justicia resuelve, señalando que:

[...] tratándose del delito de peculado son corresponsables del mismo tanto el funcionario público como el particular que no ostenta tal calidad, ya por el principio de indivisibilidad del título de la infracción, ya por principio de la comunicabilidad de las circunstancias del delito, cuando no son de orden personal sino fácticas y conocidas por el partícipe que no es funcionario público, de manera que el juzgamiento por el mismo delito de peculado hecho a los seńores Gallardo Zúńiga y Medina Clavijo es enteramente jurídico. ${ }^{70}$

Como se observa, la Corte Suprema ha dejado en claro que a través de la aplicación de la figura de la comunicabilidad de las circunstancias, quien participa del delito sin detentar la calidad de funcionario público y, al haber ejecutado actos principales, debe responder por el delito de peculado. Pues la circunstancia de funcionario público, al formar parte del tipo penal, es una de orden fáctica y, al ser conocida por el privado, debe comunicarse. Por lo tanto, es completamente legal que el privado responda como coautor del delito de peculado cometido en conjunto con el funcionario público.

A pesar de que el criterio de la Corte ha sido en su mayoría inclinado a aceptar que el privado pueda responder como autor del delito de peculado sin detentar la calificación requerida por el tipo, han existido razonamientos judiciales que difieren de esta posición. Esto se ve reflejado en la sentencia emitida por el Segundo Tribunal Penal de Manabí, la cual fue modificada por la Corte Suprema de Justicia en la resolución del recurso de casación, publicado en la Gaceta Judicial 12 Serie 16 de 1998.

67 Gaceta Judicial Año LXXIX, Serie 13, No. 5, Quito, 5 de abril de 1979, 10067.

68 Id.

69 Id

70 Juicio Penal Nro. 3-03 seguido en contra del Ing. Juan Carlos Gallardo Zúńiga y Reinaldo Enrique Medina Clavijo por el delito de peculado en perjuicios de la Dirección Provincial Agropecuaria de Cotopaxi, Corte Suprema de Justicia, Segunda Sala de lo Penal, 25 de marzo de 2004, párr. 4. 
Dentro de este proceso, en la sentencia de segunda instancia, el Segundo Tribunal Penal de Manabí condenó al privado por el delito de estafa y no lo consideró como peculado. Dividiendo, erróneamente, la infracción penal. Al respecto, la Corte, al resolver el recurso, anota que el funcionario público permitió que el privado: "cobre por trabajos no realizados en perjuicio de la Junta de Recursos Hidráulicos de Manabí, por lo que son coautores del delito de peculado" ${ }^{71}$ De esta manera, la Corte recalca que el privado, al haber participado de manera principal en la ejecución del ilícito, debe responder por el delito de peculado. Por lo tanto, la Corte Suprema de Justicia resuelve que: "el Tribunal aplicó indebidamente la Ley al haber considerado el ilícito de Zambrano Ganchozo como estafa y no como peculado". ${ }^{72}$ Demostrando una vez más que el sujeto privado sí puede responder como coautor del delito de peculado, a pesar de no poseer la calidad de funcionario público.

En un fallo más reciente, dentro del ya citado proceso No. 17721201700204 , la Corte Nacional de Justicia ha señalado que: "la calificación jurídica en el delito se hace extensiva al amparo del principio de comunicabilidad consagrado en el Art. 233 párrafo final de la CRE".$^{73}$ Esto evidencia, una vez más, que la jurisprudencia ecuatoriana ha recogido la doctrina de la comunicabilidad de las circunstancias entre los servidores públicos y el sujeto privado. Similar argumentación es la realizada por la misma Corte en el caso Filanbanco, cuando indica que en el peculado:

el sujeto activo debe reunir ciertas condiciones especiales establecidas en la ley; ahora bien, empero, los delitos, en muchas ocasiones, son ejecutados con la "participación" de otras personas, que acorde con nuestra legislación pueden ser autores; $\mathrm{y}$, los "partícipes" - palabra diferente a participación- , se dividen en cómplices y encubridores; en el sub iúdice, se encuentra que varias personas (incluidos los sindicados ahora recurrentes), han sido consideradas por el juzgador de instancia como responsables de este delito, encontrándose que no todas cumplían, en principio, con el condicionamiento de ser servidor público, para ser consideradas autoras; más sin embargo, tal aseveración que, en principio, parecería absoluta, no lo es, en tanto y en cuanto como quedó seńalado, y así lo reconoce la jurisprudencia nacional, procede lo que doctrinariamente se conoce como "comunicabilidad de circunstancias" (énfasis añadido).$^{74}$

La Corte señala que esta doctrina ha sido adoptada históricamente en la jurisprudencia ecuatoriana pero que: "[...] consta recogida en la Constitución Política de la República, de 1998 y la vigente Constitución de la República del $2008 " .{ }^{75}$ De acuerdo con el criterio de la Corte, la doctrina de la comunicabi-

71 Gaceta Judicial Año XCVIII, Serie 16, No. 12, Quito, 22 de mayo de 1998, 3123.

73 Causa No. 17721201700204, 20 de julio del 2018.

74 Causa No. 414B-2010, pág. 59.

75 Id., 58-59. 
lidad de las circunstancias se encuentra contemplada en nuestra Constitución y, por lo tanto, debería ser el criterio predominante al momento de dictar sentencia en casos similares.

\section{Conclusión}

En la comisión del delito de peculado muchas veces intervienen sujetos privados que no tienen la calificación exigida por el tipo, para facilitar el cometimiento de este. Como se ha observado en la causa 17294-2018-00704, los sujetos privados intervienen en el cometimiento del ilícito de tal manera que, sin sus actos, el delito no hubiese sido posible. Por lo tanto, si la participación de los privados en el delito de peculado tiene tal trascendencia, excluirlos de la condena sería dejar en la impunidad sus conductas. Por esta razón, los Tribunales y las Cortes del Ecuador han adoptado una posición similar que determina que los privados, que no son funcionarios públicos, sí pueden ser sentenciados como coautores del delito de peculado.

A pesar de que la posición parece estar inclinada a aceptar la condena de privados como coautores del delito, los diferentes argumentos utilizados para justificar estas decisiones son varios. La adopción de la jurisprudencia de la figura del intraneus y extraneus es sumamente interesante. Al comparar su uso con lo dispuesto por la doctrina penal, se observa que es un argumento fuerte para condenar a los privados como coautores del delito. Tanto el Tribunal de Garantías Penales como la Corte Provincial de Pichincha, en el caso analizado, adoptaron una correcta posición respecto a este tema, demostrando que la intervención del extraneus en el delito de peculado no puede ser dejada de lado y, por lo tanto, debe ser tratada como coautoría, siempre y cuando los actos del privado sean principales en la ejecución del delito.

Por otro lado, la argumentación utilizada por diferentes tribunales y cortes sobre la comunicabilidad de las circunstancias es, de igual manera, muy acertada. Pues si el interviniente que no ostenta la calificación de funcionario público conoce que el sujeto con quien divide el trabajo para cometer el ilícito es un funcionario público, lo lógico sería que el privado responda por sus actos encaminados a cometer el peculado.

El artículo 233 de la Constitución parece, en principio, haber solucionado el dilema respecto a la intervención del sujeto privado en la comisión del peculado, pues al dar un alcance de las normas sobre peculado a los privados, parecería que posibilita que estos sí pueden responder como coautores. Sin embargo, aquí surge la interrogante sobre si el artículo 233 amplifica la tipicidad del tipo a los extraneus solo como cómplices del delito o si únicamente se refiere a la aplicación de las reglas de imprescriptibilidad y juzgamiento 
en ausencia. No obstante, como se observó en las sentencias emitidas por la Corte Provincial de Pichincha y la Corte Nacional de Justicia, la intención del constituyente parece haber sido que los actos de los privados no queden en la impunidad y que estos sí puedan responder como coautores del delito, siempre y cuando sus actos se adecuen a esta figura. 